\title{
Integration of a Three-Dimensional-Printed Titanium Implant in Human Tissues: Case Study
}

\author{
Jong Woong Park ${ }^{1,2} \oplus$, Chae Ahn Song ${ }^{2}$, Hyun Guy Kang ${ }^{1,2, *}$, June Hyuk Kim ${ }^{1}$, \\ Kwun Mook Lim $^{3}$ and Han-Soo Kim ${ }^{4}$ \\ 1 Orthopaedic Oncology Clinic, Center for Rare Cancers, National Cancer Center, 323 Ilsan-ro, Ilsandong-gu, \\ Goyang-si Gyeonggi-do 10408, Korea; jw.snumed@gmail.com (J.W.P.); docjune@ncc.re.kr (J.H.K.) \\ 2 Division of Convergence Technology, Research Institute, National Cancer Center, Goyang 10408, Korea; \\ gusal2348@ncc.re.kr \\ 3 Medyssey Company, Chungcheongbuk-do 27116, Korea; 1km@medyssey.com \\ 4 Department of Orthopaedic Surgery, Seoul National University Hospital, Seoul 03080, Korea; \\ hankim@snu.ac.kr \\ * Correspondence: ostumor@ncc.re.kr; Tel.: +82-31-920-1665; Fax: +82-31-920-2798
}

Received: 9 December 2019; Accepted: 9 January 2020; Published: 11 January 2020

\begin{abstract}
A titanium alloy implant of appropriate pore size can potentially enhance osseointegration and soft tissue integration. However, the human clinical application of such implants has not been reported. Here, we present a case of limb salvage surgery for a bone tumor using customized three-dimensional (3D)-printed Ti6Al4V radius and ulna implants. The patient presented with local recurrence at the proximal junction of the ulna and underwent a re-wide excision. Single forearm bone surgery was performed using another 3D-printed implant after resection of the recurrent tumor with an ulnar implant. Host osseointegration and soft tissue integration of the retrieved implant were quantified through histological evaluation. The total tissue integration rates of the implant at the proximal and distal bone junctions were $45.96 \%$ and $15.03 \%$, respectively. The mesh structure enhanced bone integration by up to $10.81 \%$ in the proximal and by up to $8.91 \%$ in the distal bone junction. Furthermore, the soft tissue adhesion rates of the implant shaft were $59.50 \%$ and $50.26 \%$ in the axial and longitudinal cuts, respectively. No area was left unoccupied throughout the shaft of the implant. Overall, these results indicate that the 3D-printed Ti6Al4V titanium alloy implant with a rough surface has considerable tissue integration ability.
\end{abstract}

Keywords: three-dimensional printing; bone tumor; implant; tissue integration; titanium; human

\section{Introduction}

Three-dimensional (3D) printing technology is rapidly advancing in the medical field [1-5]. In orthopedic surgery, 3D printing is now widely performed to customize implants [6-10]. This novel additive manufacturing method facilitates the rapid and cost-effective fabrication of customized implants [3,11-16]. Unlike the traditional metal casting method, 3D printing technology facilitates the production of implants with a constant internal pore. A few in vitro studies and in vivo animal experiments have demonstrated the potential of a titanium alloy implant with appropriate porosity to enhance the osseointegration of implants [11,12,15,17-21]. Some studies have developed titanium alloy implants with a bioactive coating-however, animal and in vitro studies on these implants are still underway [22-24].

Soft tissue adhesion is essential for limb salvage surgery in treating orthopedic tumors to effectively reestablish the muscle origins or insertions that are detached during surgical tumor resection. Furthermore, soft tissue adhesion can reduce the dead space to prevent postoperative infection. The 
Trevira tube is a specially designed surgical envelope that has been widely used for this purpose to enhance the attachment of soft tissue around megaprostheses [25]. However, to our knowledge, no study has evaluated the integration of a 3D-printed titanium implant in human bones and soft tissues.

Here, we report the successful osseointegration and soft tissue integration ability of a 3D-printed titanium implant during limb salvage surgery in treatment of a bone tumor and demonstrate the potential of this implant to appropriately design the host bone junction and implant surface.

\section{Materials and Methods}

\subsection{Patient Information}

A 40-year-old man presented with two-week long paresthesia in his right hand and limited forearm rotation. The patient demonstrated a limited motion range of the elbow and forearm due to dislocation of the radial head that was attributed to a traumatic injury during childhood. Five years prior, he underwent orthopedic surgery employing an external fixator to repair a traumatic fracture in his right wrist. Although the range of motion of his elbow and forearm was already limited, further exacerbation was evident upon presentation. Magnetic resonance imaging (MRI) revealed an infiltrative tumor on his forearm that affected both the radius and ulna. The tumor, which was presumed to have originated from the external fixator pin site of the radius, was later confirmed as being a desmoplastic fibroma of the bone through core needle biopsy. No distant metastasis was observed. Although gain of function could not be guaranteed by reconstruction of both forearm bones, the patient nevertheless opted for anatomical reconstruction because of the already limited range of motion of the affected forearm prior to tumor presentation.

Limb salvage surgery was performed with 3D-printed customized implants for both forearm bones, excluding the wrist and elbow joints (Figure 1A,B). The details of implant design, production, and verification for this patient are provided in our previous study [26]. A routine postoperative evaluation revealed local recurrence around the shaft of the proximal ulna within a year. Therefore, the patient underwent another limb salvage surgery, in which a single forearm bone was reconstructed in fusion of remaining distal radius and proximal ulna with a functional position following removal of the ulnar implant with the recurred tumor (Figure 2A-C). The institutional review board of our institute approved this study, and the patient provided written informed consent (NCC2017-0129).
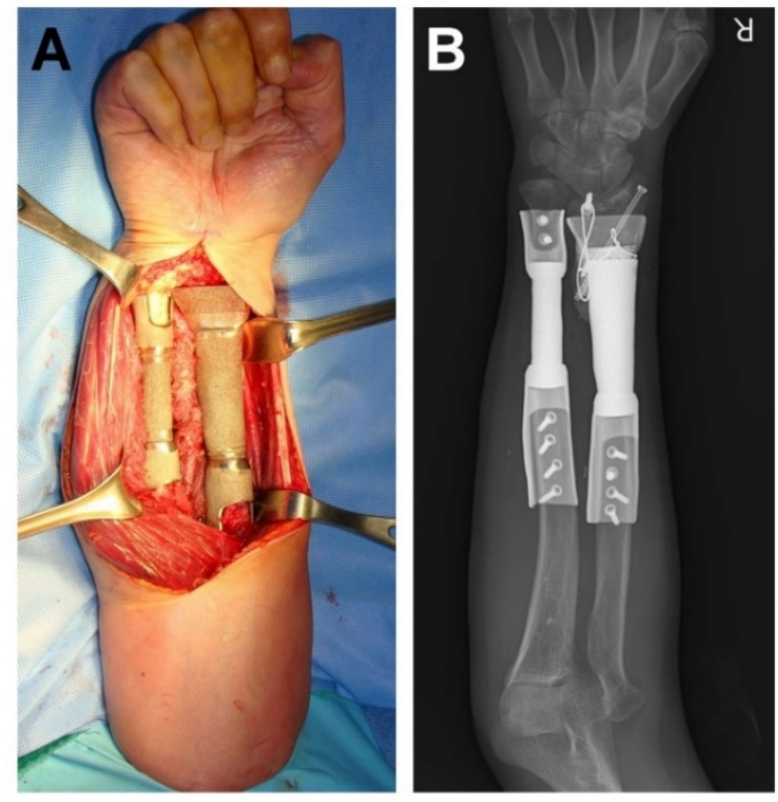

Figure 1. Primary surgery. (A) Intraoperative photograph and (B) postoperative plain radiograph showing the general configuration of an implant. 


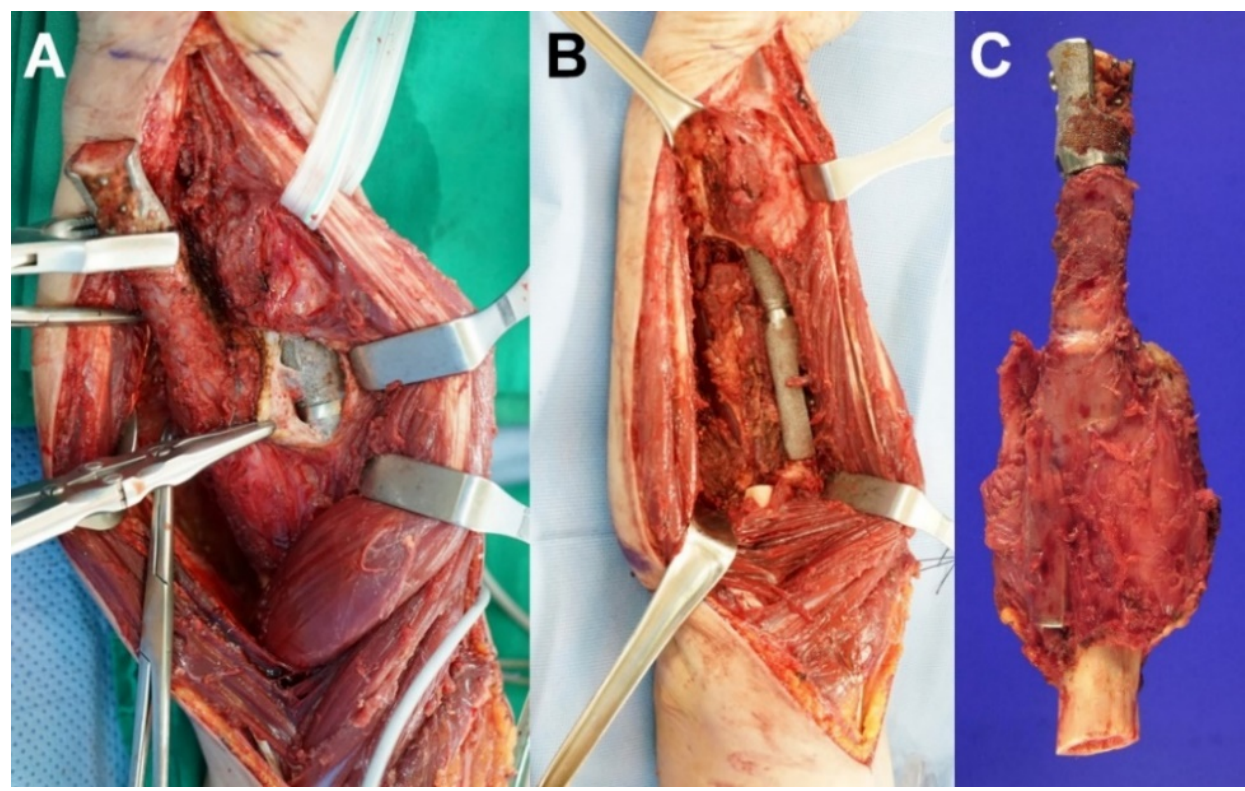

Figure 2. Revisional surgery. Photographs showing (A) wide excision of the ulnar implant, (B) the soft tissue bed after resection of the recurred tumor, and (C) the retrieved ulnar implant with the recurred tumor.

\subsection{Implant Design and Fabrication}

Preoperative computed tomography (CT) and MR images were obtained to design implants for the radius and ulna. Virtual bone cutting was performed with an adequate bone margin; the implant shape was derived from the mirror images of contralateral normal bones [10]. To enhance the immediate fixation strength and promote osteogenesis, the bone junction was designed to contain a half-cylindrical plate with multiple screw holes and a 1-cm skirt to surround the end of the host bone at the base of the plate (Figure 3A,B). A mesh with an edge length of $2.5 \mathrm{~mm}$ (dode-thin structure; Magics RP 22, Materilaise, Belgium) was used for the surface at the end of the host bone (Figure 3C). The implant body and half-cylindrical plates had a robust structure with a rough surface (average roughness of $48 \mathrm{~nm}$ ). The implant was fabricated using an electron melting beam 3D printer system (ARCAM A1, Arcam AB, Mölndal, Sweden) and Ti6Al4V metal powder. The length and weight of the final implant were $15 \mathrm{~cm}$ and $67 \mathrm{~g}$, respectively.
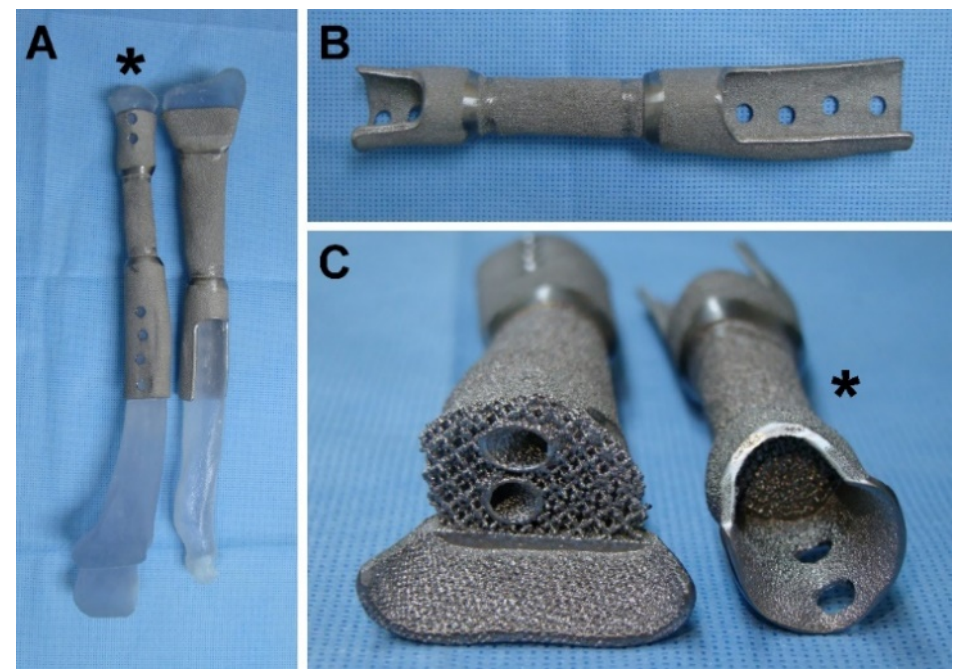

Figure 3. Bone implants of the radius and the ulna. Photographs showing (A) 3D-printed implants of both forearm bones with the host bone models, (B) a volar view of the ulnar implant, and (C) the mesh-structured junctional area of the implants. The asterisk $\left({ }^{*}\right)$ indicates the ulnar implant. 


\subsection{Quantitative Analysis of Tissue Integration}

To evaluate osseointegration, the titanium alloy implant, along with the surrounding tissues, was cut and pathologically analyzed. The retrieved implant and surrounding tissues were fixed in $10 \%$ buffered neutralized formalin. The implant with adjacent ulnar fragments was placed in paraffin to generate a 6- $\mu \mathrm{m}$-thick specimen. Specimens of the proximal and distal junctional regions were generated through longitudinal sectioning (Figure $4 \mathrm{~A}-\mathrm{C}$ and Figure $5 \mathrm{~A}-\mathrm{C}$ ). Transverse and longitudinal sections were analyzed for the middle implant body (Figure 6A,B) through staining with Weight's hematoxylin (nuclei staining) and Ponceau Acid Fuchsin solution using Goldner's trichrome method. The tissues are stained red and blue; mature bone is stained blue. The red-stained areas with and without osteocytes were classified as premature bone and fibrous tissue, respectively.

The porous surface of the implant for each segment of the proximal and distal junctional regions (Proximal [P] 1-5 for the proximal bone implant area; Distal [D] 1-5 for the distal bone-implant area) was examined (Figures 4C and 5C). To quantify integration, the rates of bone-to-implant contact (BIC, $\%$ ), soft tissue-to-implant contact (SIC, \%), and total contact (TC, \%) were calculated by dividing the bone, soft tissue, and total contact lengths of each segment on the basis of their corresponding metal surface lengths. Moreover, as the middle shaft specimens were bone-free, only the SIC rate was used to analyze soft tissue integration of the implant (Figure 6A,B).
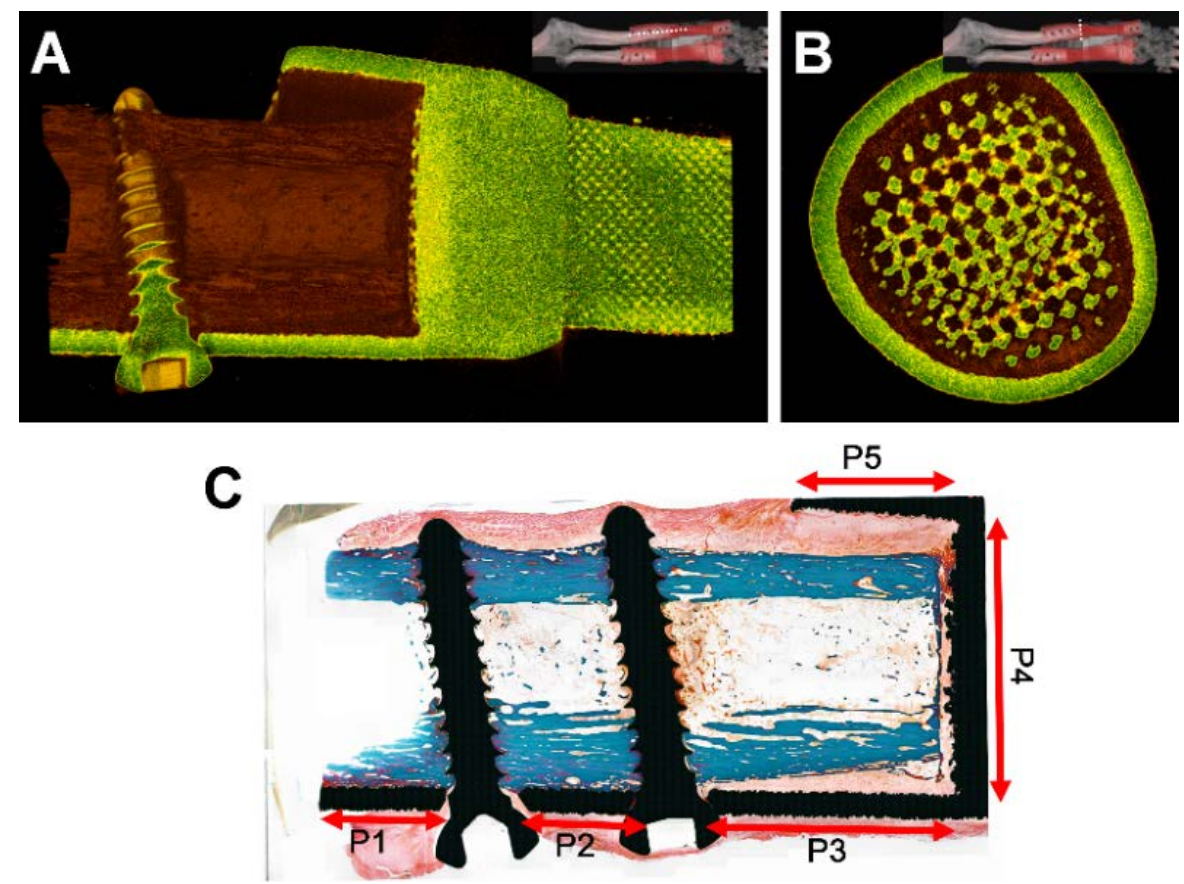

Figure 4. Analyzed segments of the proximal region. Micro-computed tomographic images showing (A) the longitudinal view and (B) axial view, with scout images in the upper right corner. Photomicrograph ((C): Goldner's trichrome staining, $1 \times$ magnification) of the histological specimen of the longitudinal section showing the analyzed segments (P1-P5). 

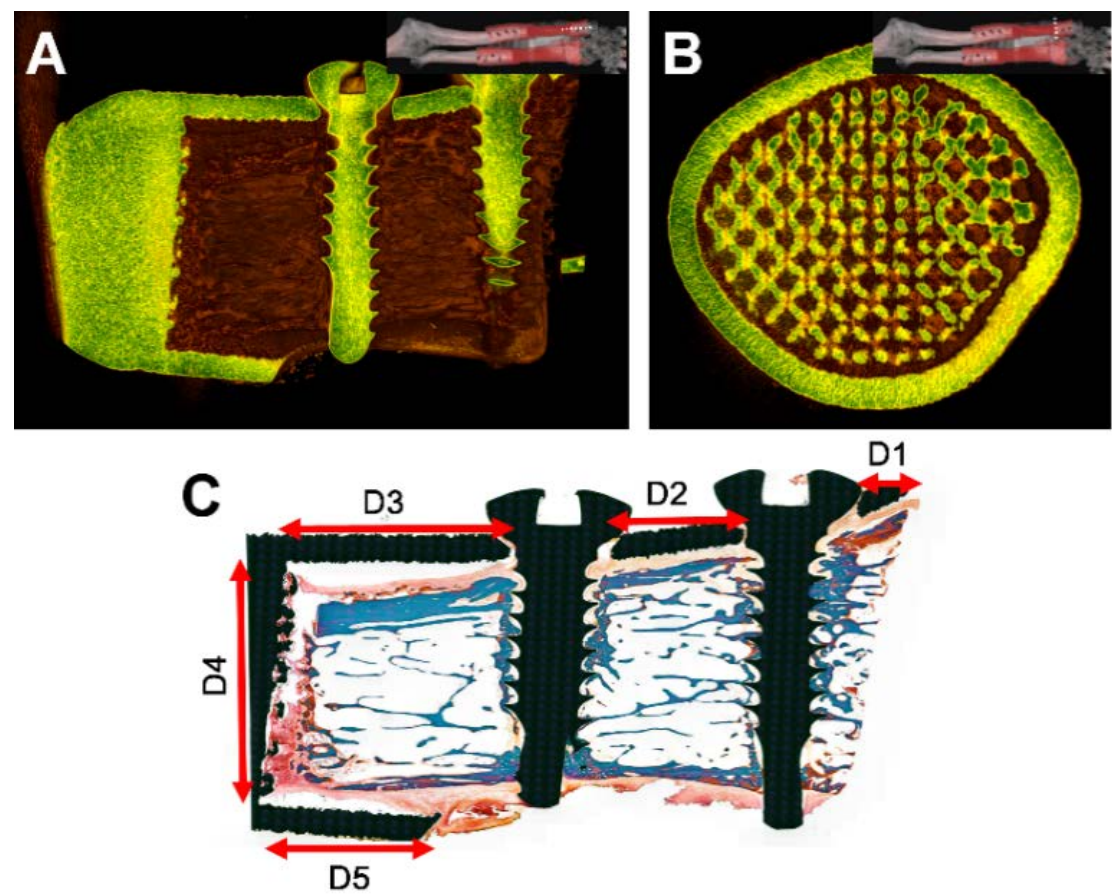

D1

Figure 5. Analyzed segments of the distal region. Micro-computed tomographic images showing (A) a longitudinal view and (B) axial view, with scout images in the upper right corners. Photomicrograph ((C): Goldner's trichrome staining, 1× magnification) of the histological specimen of the longitudinal section showing the analyzed segments (D1-D5).
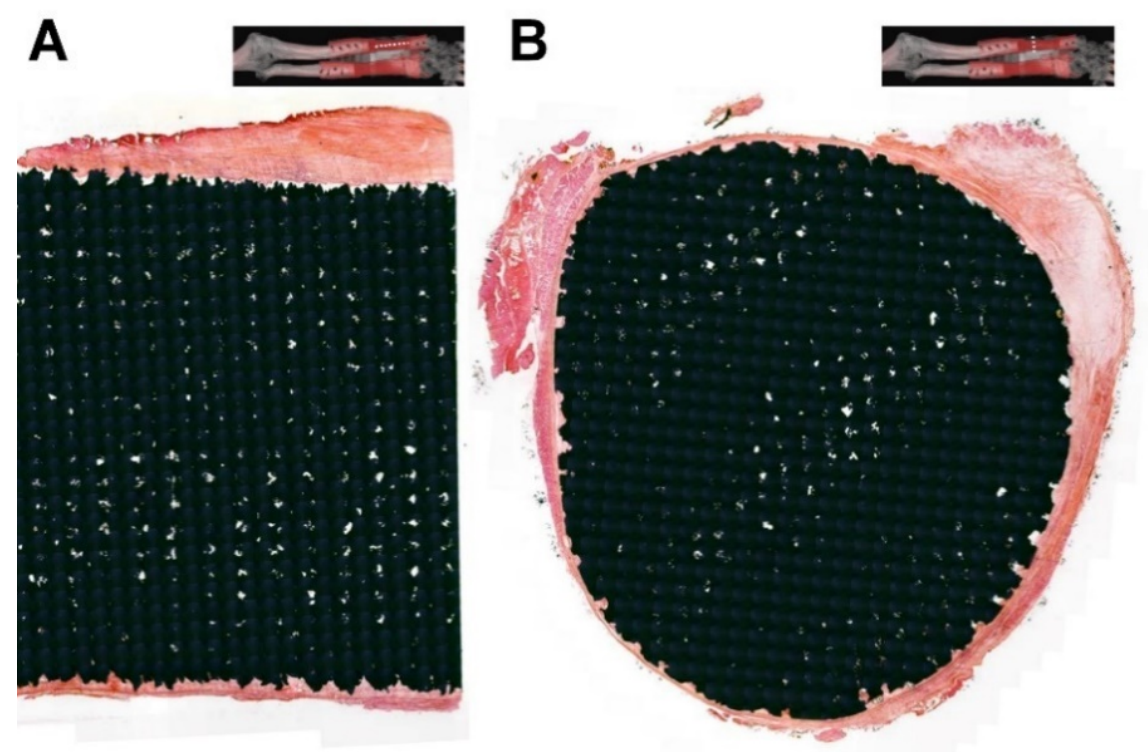

Figure 6. Analyzed sections of the ulnar implant shaft. Photomicrograph ((A,B): Goldner's trichrome staining, $1 \times$ magnification) of the histological specimens of the longitudinal and axial sections, with scout images in the upper right corners showing soft tissue adhesion without the uncovered area.

\section{Results}

\subsection{Bone Contact Surface}

The TC rates for the whole proximal and distal junctions were $45.96 \%$ and $15.03 \%$, respectively, and those for the mesh structured segments (P4 and D4) were $82.05 \%$ and 16.92\%, respectively. Total tissue integration involves osseous union (bone-to-implant contact, BIC) and fibrous union 
(soft tissue-to-implant contact, SIC). Osseous union was observed in the P1, P2, P4, and D4 segments, whereas only fibrous union was revealed in the other segments. The P1 and P2 segments exhibited rough surfaces without the mesh, however, gaps between the metal implant and the host bone were almost absent. A mesh was utilized to enhance osseointegration to the P4 and D4 segments, and the measured gaps for these segments were $0.2-0.5$ and $0.7-1.2 \mathrm{~mm}$, respectively. The BIC rates for the mesh-enhanced P4 and D4 segments were $10.81 \%$ and $8.91 \%$, respectively. For rough surfaces without the mesh, segments with accurate contact between the host bone and implant presented osseointegration ( $21.93 \%$ for P1, 26.47\% for P2). However, other rough surfaces with a gap between the bone and the implant did not present osseointegration (Figures $4 \mathrm{C}$ and 5C and Table 1).

Table 1. Measurements for the 3D-printed implant and bone contact surfaces.

\begin{tabular}{cccc}
\hline Measured Segment & BIC (\%) & SIC (\%) & TC (\%) \\
\hline Proximal & & & \\
P1 & 21.93 & 0 & 21.93 \\
P2 & 26.47 & 0 & 26.47 \\
P3 & 0 & 60.77 & 60.77 \\
P4 & 10.81 & 71.24 & 82.05 \\
P5 & 0 & 21.53 & 21.53 \\
\hline Overall & 8.47 & 37.5 & 45.97 \\
\hline Distal & & & \\
D1 & 0 & 34.13 & 34.13 \\
D2 & 0 & 50.81 & 50.81 \\
D3 & 0 & 0 & 0 \\
D4 & 8.91 & 8.01 & 16.92 \\
D5 & 0 & 1.74 & 1.74 \\
\hline Overall & 2.32 & 12.71 & 15.03 \\
\hline
\end{tabular}

BIC: rate of bone-to-implant contact, SIC: rate of soft tissue-to-implant contact, TC: rate of total contact.

\subsection{Soft Tissue Contact Surface}

The soft tissue surrounded the shaft of the implant and was firmly attached to the implant surface. The SIC rates for the axial and longitudinal cuts were $59.50 \%$ and $50.26 \%$, respectively. No area of the implant shaft was left uncovered by the soft tissue (Figure 6A,B).

\section{Discussion}

The 3D printing method for producing Ti6Al4V titanium alloy implants has been recently used for clinical applications. Because 3D printing is an additive manufacturing technique, the porosity and roughness of a surface can be appropriately adjusted using this technique. Previous studies have reported that a titanium alloy implant with appropriate porosity or roughness can enhance tissue integration $[11,12,15,17-21]$. However, to our knowledge, this potential has not yet been evaluated in a clinical application in humans. In this study, a retrieved 3D-printed titanium alloy implant from the human forearm was histologically analyzed for its osseointegration and soft tissue integration ability. The junctional region of this implant comprised a semi-circular patient-specific skirted plate and a mesh structure at the edge of the bone contact surface. Major considerations during the follow-up period included bone remodeling at the bony ends of the host and osteo/fibrosynthetic effects caused by the mesh structure or the roughness of the implant surface.

An appropriate pore structure is important to overcome small gaps that are formed between the implant and the host bone. We observed that osteointegration with such small gaps was achieved at segments containing the mesh structure but not at those not containing the mesh structure. A few animal studies have previously focused on the osteointegration of a 3D-printed titanium implant $[11,12,15,20,21,27]$, and three of these specifically focused on using vertebral cages for flat 
bones $[12,15,20]$. However, it is difficult to compare the results of these studies with those of the present study, which used the long tubular bone. Another experimental animal study exhibited bone ingrowth at the cortical surface of flat bones and at the implant contact area [21,27]. Herein, the total bone growth rate was less than $10 \%$, and the osseointegration rate for the implant most proximal to the host bone bed was approximately $20 \%$. Another study focused on osseointegration in the long bones of animals in accordance with the pore size of the implant produced through selective laser sintering, a 3D printing method [11]. Therein, the small and large implant pores had diameters of $700 \mu \mathrm{m}$ and $1500 \mu \mathrm{m}$, respectively, and the osseointegration rates were $32.2 \%(72.4 \mathrm{~mm} / 224.9 \mathrm{~mm})$ and $40.6 \%$ (42.9 $\mathrm{mm} / 105.7 \mathrm{~mm})$, respectively. In the present study, the pore size of the meshed region of the implant was observed to be $2200 \mu \mathrm{m}(2.2 \mathrm{~mm})$, which is greater than that of the large pores in the aforementioned study. Because of several differences between the two studies, such as pore size, recipient species (sheep vs. human), and implant design (exterior collar vs. internal contact surface), direct comparison of osseointegration rates did not yield significant results. However, implant osseointegration was nevertheless achieved upon overcoming small gaps between the implant and host bone, concurrent with previous studies.

The novel design of the present implant enhanced the structural mechanical strength properties and thus can potentially protect against cortical atrophy. A half plate with a skirt at the base was utilized at the junctional site between the implant and the host bone. A temporary reduction of the implant to the bone defect was easily achieved by inserting the bony end into the skirt during screw fixation. Moreover, both ends of the host bone did not present cortical atrophy in serial plain radiographs during a 1-year postoperative follow-up evaluation. Several studies have reported the occurrence of cortical atrophy, a common bone remodeling pattern, at the end of the host bone following limb salvage surgery for long bone extremities [28-31]. Cortical atrophy can result from stress shielding, surgical damage of the periosteum, or impaired blood supply. To protect against cortical bone atrophy, the skirt of the presenting 3D-printed implant surrounding the host bone was designed to provide a large bone contact surface for osseointegration and even stress distribution. However, postoperative follow-up evaluation after one year revealed that the small gap between the rough surface of the skirt and the host cortical surface induced the growth of fibrous tissue rather than new bone formation. Therefore, long-term follow-up evaluation is needed to determine whether this fibrous tissue induces cortical atrophy or cortical bone thickening.

Considerable soft tissue adhesion around the implant and fibrous scar tissue was observed. The reattachment of soft tissues to the implant, including tendons, ligaments, joint capsules, and muscles, using the Trevira tube (Attachment tube; Implantcast, Buxtehude, Germany) served as a reliable surgical alternative [25]. However, 3D-printed implants with a rough surface (roughness average of $48 \mathrm{~nm}$ ) showed direct and robust attachment to the soft tissue without the need for additional material. Moreover, rough and smooth surfaces can be customized throughout 3D-printed implants, such that they are expected to be selectively attached to muscle and joint capsules while preventing the adhesion of neurovascular bundles. Further clinical experience is required to determine whether the histological characteristics of soft tissue adhesion facilitate functional rehabilitation.

This study has some limitations. This was a case report of only one patient. Because of ethical considerations, it is difficult to further investigate the tissue integration of 3D-printed implants in humans. To our knowledge, no study has quantitatively analyzed tissue integration of implants in humans. Another major limitation of this study is that we did not perform mechanical tests to compare the adhesion strength and tensile force. Mechanical experiments and histological evaluation could not be performed because of the limited availability of specimens. Ultimately, a histological quantitative analysis was accurately performed as it was considered to be more valuable than mechanical tests, which can damage adhesive tissues. 


\section{Conclusions}

In conclusion, this study shows that minimization of the gap between the implant and host bone is essential for high osseointegration achieved by a 3D-printed implant, and a mesh structure could help overcome small gaps.

Author Contributions: Conceptualization, J.W.P., C.A.S., and H.G.K.; Methodology, J.W.P. and C.A.S.; Software, K.M.L.; Validation, J.W.P., H.G.K., J.H.K. and H.-S.K.; Formal Analysis, J.W.P.; Investigation, J.W.P. and C.A.S.; Resources, J.W.P., C.A.S., and K.M.L.; Data Curation, J.W.P. and C.A.S.; Writing-Original Draft Preparation, J.W.P. and C.A.S.; Writing-Review \& Editing, J.W.P. and H.G.K.; Visualization, J.W.P.; Supervision, H.G.K.; Project Administration, J.W.P. and H.G.K.; Funding Acquisition, J.W.P. and H.G.K. All authors have read and agreed to the published version of the manuscript.

Funding: This study was supported by a grant from the Korea Health Technology R\&D Project through the Korea Health Industry Development Institute (KHIDI) and by the Ministry of Health \& Welfare, Republic of Korea (grant number: HI17C1823). This study was supported in part by a National Cancer Center Grant (NCC-1911880).

Conflicts of Interest: The authors declare no conflict of interest.

\section{References}

1. Kwon, B.J.; Seon, G.M.; Lee, M.H.; Koo, M.A.; Kim, M.S.; Kim, D.; Han, J.J.; Kim, D.; Kim, J.; Park, J.C. Locally delivered ethyl-2,5-dihydroxybenzoate using 3D printed bone implant for promotion of bone regeneration in a osteoporotic animal model. Eur. Cell Mater. 2018, 35, 1-12. [CrossRef] [PubMed]

2. Long, M.; Rack, H.J. Titanium alloys in total joint replacement-a materials science perspective. Biomaterials 1998, 19, 1621-1639. [CrossRef]

3. Murr, L.E.; Gaytan, S.M.; Medina, F.; Lopez, H.; Martinez, E.; Machado, B.I.; Hernandez, D.H.; Martinez, L.; Lopez, M.I.; Wicker, R.B.; et al. Next-generation biomedical implants using additive manufacturing of complex, cellular and functional mesh arrays. Philos. Trans. Ser. Amath. Phys. Eng. Sci. 2010, 368, 1999-2032. [CrossRef] [PubMed]

4. Ravichandran, R.; Ng, C.; Liao, S.; Pliszka, D.; Raghunath, M.; Ramakrishna, S.; Chan, C.K. Biomimetic surface modification of titanium surfaces for early cell capture by advanced electrospinning. Biomed. Mater. 2012, 7, 015001. [CrossRef] [PubMed]

5. Park, J.W.; Kang, H.G.; Lim, K.M.; Park, D.W.; Kim, J.H.; Kim, H.S. Bone tumor resection guide using three-dimensional printing for limb salvage surgery. J. Surg. Oncol. 2018, 118, 898-905. [CrossRef] [PubMed]

6. Wong, K.C.; Kumta, S.M.; Sze, K.Y.; Wong, C.M. Use of a patient-specific CAD/CAM surgical jig in extremity bone tumor resection and custom prosthetic reconstruction. Comput. Aided Surg. Off. J. Int. Soc. Comput. Aided Surg. 2012, 17, 284-293. [CrossRef]

7. Wong, K.C.; Kumta, S.M.; Geel, N.V.; Demol, J. One-step reconstruction with a 3D-printed, biomechanically evaluated custom implant after complex pelvic tumor resection. Comput. Aided Surg. Off. J. Int. Soc. Comput. Aided Surg. 2015, 20, 14-23. [CrossRef]

8. Wei, R.; Guo, W.; Ji, T.; Zhang, Y.; Liang, H. One-step reconstruction with a 3D-printed, custom-made prosthesis after total en bloc sacrectomy: A technical note. Eur. Spine J. Off. Publ. Eur. Spine Soc. Eur. Spinal Deform. Soc. Eur. Sect. Cerv. Spine Res. Soc. 2017, 26, 1902-1909. [CrossRef]

9. Imanishi, J.; Choong, P.F. Three-dimensional printed calcaneal prosthesis following total calcanectomy. Int. J. Surg. Case Rep. 2015, 10, 83-87. [CrossRef]

10. Park, J.W.; Kang, H.G.; Lim, K.M.; Kim, J.H.; Kim, H.S. Three-Dimensionally Printed Personalized Implant Design and Reconstructive Surgery for a Bone Tumor of the Calcaneus: A Case Report. Jbjs Case Connect. 2018, 8, e25. [CrossRef]

11. Mumith, A.; Coathup, M.; Chimutengwende-Gordon, M.; Aston, W.; Briggs, T.; Blunn, G. Augmenting the osseointegration of endoprostheses using laser-sintered porous collars: An in vivo study. Bone Jt. J. 2017, 99, 276-282. [CrossRef] [PubMed]

12. McGilvray, K.C.; Easley, J.; Seim, H.B.; Regan, D.; Berven, S.H.; Hsu, W.K.; Mroz, T.E.; Puttlitz, C.M. Bony ingrowth potential of 3D-printed porous titanium alloy: A direct comparison of interbody cage materials in an in vivo ovine lumbar fusion model. Spine J. 2018, 18, 1250-1260. [CrossRef] [PubMed] 
13. Li, S.J.; Murr, L.E.; Cheng, X.Y.; Zhang, Z.B.; Hao, Y.L.; Yang, R.; Medina, F.; Wicker, R.B. Compression fatigue behavior of Ti-6Al-4V mesh arrays fabricated by electron beam melting. Acta Mater. 2012, 60, 793-802. [CrossRef]

14. Koike, M.; Greer, P.; Owen, K.; Lilly, G.; Murr, L.E.; Gaytan, S.M.; Martinez, E.; Okabe, T. Evaluation of Titanium Alloys Fabricated Using Rapid Prototyping Technologies-Electron Beam Melting and Laser Beam Melting. Materials 2011, 4, 1776-1792. [CrossRef] [PubMed]

15. Li, S.; Li, X.; Hou, W.; Nune, K.C.; Misra, R.D.K.; Correa-Rodriguez, V.L.; Guo, Z.; Hao, Y.; Yang, R.; Murr, L.E. Fabrication of open-cellular (porous) titanium alloy implants: Osseointegration, vascularization and preliminary human trials. Sci. China Mater. 2018, 61, 525-536. [CrossRef]

16. Sing, S.L.; An, J.; Yeong, W.Y.; Wiria, F.E. Laser and electron-beam powder-bed additive manufacturing of metallic implants: A review on processes, materials and designs. J. Orthop. Res. 2016, 34, 369-385. [CrossRef]

17. Lee, Y.H.; Chung, C.J.; Wang, C.W.; Peng, Y.T.; Chang, C.H.; Chen, C.H.; Chen, Y.N.; Li, C.T. Computational comparison of three posterior lumbar interbody fusion techniques by using porous titanium interbody cages with 50\% porosity. Comput. Biol. Med. 2016, 71, 35-45. [CrossRef]

18. Guyer, R.D.; Abitbol, J.J.; Ohnmeiss, D.D.; Yao, C. Evaluating Osseointegration Into a Deeply Porous Titanium Scaffold: A Biomechanical Comparison With PEEK and Allograft. Spine 2016, 41, E1146-E1150. [CrossRef]

19. Tsou, H.K.; Chi, M.H.; Hung, Y.W.; Chung, C.J.; He, J.L. In Vivo Osseointegration Performance of Titanium Dioxide Coating Modified Polyetheretherketone Using Arc Ion Plating for Spinal Implant Application. BioMed Res. Int. 2015, 2015, 328943. [CrossRef]

20. Wu, S.H.; Li, Y.; Zhang, Y.Q.; Li, X.K.; Yuan, C.F.; Hao, Y.L.; Zhang, Z.Y.; Guo, Z. Porous titanium-6 aluminum-4 vanadium cage has better osseointegration and less micromotion than a poly-ether-ether-ketone cage in sheep vertebral fusion. Artif. Organs 2013, 37, E191-E201. [CrossRef]

21. Li, J.P.; Habibovic, P.; van den Doel, M.; Wilson, C.E.; de Wijn, J.R.; van Blitterswijk, C.A.; de Groot, K. Bone ingrowth in porous titanium implants produced by 3D fiber deposition. Biomaterials 2007, 28, 2810-2820. [CrossRef] [PubMed]

22. Popkov, A.V.; Popkov, D.A.; Kononovich, N.A.; Gorbach, E.N.; Tverdokhlebov, S.I.; Bolbasov, E.N.; Darvin, E.O. Biological activity of the implant for internal fixation. J. Tissue Eng. Regen Med. 2018, 12, 2248-2255. [CrossRef] [PubMed]

23. Kumar, A.; Nune, K.C.; Misra, R.D.K. Design and biological functionality of a novel hybrid Ti-6Al-4V/hydrogel system for reconstruction of bone defects. J. Tissue Eng. Regen Med. 2018, 12, 1133-1144. [CrossRef] [PubMed]

24. Cheng, A.; Humayun, A.; Boyan, B.D.; Schwartz, Z. Enhanced Osteoblast Response to Porosity and Resolution of Additively Manufactured Ti-6Al-4V Constructs with Trabeculae-Inspired Porosity. 3D Print. Addi. Manuf. 2016, 3, 10-21. [CrossRef] [PubMed]

25. Gosheger, G.; Hillmann, A.; Lindner, N.; Rodl, R.; Hoffmann, C.; Burger, H.; Winkelmann, W. Soft tissue reconstruction of megaprostheses using a trevira tube. Clin. Orthop. Relat. Res. 2001, 264-271. [CrossRef] [PubMed]

26. Lim, K.M.; Park, J.W.; Park, S.J.; Kang, H.G. 3D-Printed Personalized Titanium Implant. Design, Manufacturing and Verification for Bone Tumor Surgery of Forearm. Biomed J. Sci. Tech. Res. 2018, 10. [CrossRef]

27. Michael, D.W.; Simon, Z.; Jasmine, R.; Ralf, S.; Thea, F.; Chafik, G.; Weber, F.E. Influence of Microarchitecture on Osteoconduction and Mechanics of Porous Titanium Scaffolds Generated by Selective Laser Melting. 3D Print. Addit. Manuf. 2016, 3, 142-151. [CrossRef]

28. Jones, K.B.; Buckwalter, J.A. Severe periprosthetic cortical atrophy in the skeletally immature: A report of three cases. Iowa Orthop. J. 2005, 25, 75-81.

29. Kim, W.; Han, I.; Cho, H.S.; Kang, S.; Kim, H.S. Cortical Atrophy Related to Tumor Prosthesis in Skeletally Immature Osteosarcoma Patients. J. Pediatr. Orthop. 2018, 38, 60-68. [CrossRef]

30. Capanna, R.; Morris, H.G.; Campanacci, D.; Del Ben, M.; Campanacci, M. Modular uncemented prosthetic reconstruction after resection of tumours of the distal femur. J. Bone Jt. Surg. 1994, 76, 178-186. [CrossRef]

31. Franzen, H.; Carlsson, A.; Johnsson, R.; Rydholm, A.; Onnerfalt, R. Bony atrophy after mega total hip replacement for bone tumors: 11 cases followed for 3-15 years. Acta Orthop. Scand. 1994, 65, 513-516. [CrossRef] 